\title{
Low-dose CT angiography: sufficient contrast for vessel imaging?
}

\author{
E. E. van der Wall · J. D. Schuijf · J. J. Bax
}

Received: 14 April 2009/Accepted: 14 April 2009/Published online: 15 May 2009

(C) The Author(s) 2009. This article is published with open access at Springerlink.com

At present, noninvasive CT angiography has been shown to be as accurate as conventional angiography, and it had been presaged that CT angiography will soon be able to replace conventional coronary angiography [1-21]. The ACCURACY trial showed in 230 patients a $99 \%$ negative predictive value for CT angiography, establishing this method as an effective noninvasive alternative to conventional angiography to rule out obstructive coronary artery disease [22]. Despite the tremendous achievements by CT angiography, most investigators have called for restricted use of this imaging method until adequate clinical evidence becomes available showing the cost-effectiveness and safety of this approach. In particular, there are inherent questions about safety of cardiac CT scans in terms of radiation exposure $[23,24]$. The median exposure of CT angiography is roughly equivalent to 600 chest X-rays $(12 \mathrm{mSv})$. Traditional angiography exposes patients to roughly half the dose of CT angiography. However, the radiation exposure of almost 2,000 people having 64-slice cardiac CT images at 50 medical centers in

Editorial comment to the article of Herzog/Kaufmann et al. (doi: 10.1007/s10554-009-9460-3).

E. E. van der Wall $(\bowtie) \cdot$ J. D. Schuijf · J. J. Bax Department of Cardiology, Leiden University Medical Center, P.O. Box 9600, Leiden, The Netherlands e-mail: e.e.van_der_wall@lumc.nl different countries may vary more than six-fold [25]. Effective strategies to reduce radiation dose are available but these strategies are not frequently used. The following strategies and new scanning techniques have been proposed for dose reduction in cardiac CT and include the following [26]: (1) coronary CT angiography should not be performed in patients with extensive coronary calcifications because the probability to rule out obstructive coronary artery disease diminishes with increasing coronary artery calcium scores; (2) the scan length in CT angiography should be individually adjusted to the minimum needed length; (3) electrocardiogramcorrelated modulation of the tube current should be applied in all patients with stable sinus rhythm; (4) the tube voltage should be reduced to $100 \mathrm{kV}$ in nonobese patients (patient weight $<85-90 \mathrm{~kg}$ ); and (5) a sequential scan mode with prospective electrocardiogram triggering should be considered in patients with a stable heart rate $<$ or $=63$ beats $/ \mathrm{min}$. Pflederer et al. [27] compared the image quality of dual-source CT coronary angiography using $100 \mathrm{kV}$ instead of $120 \mathrm{kV}$ in 100 patients. The authors showed that the use of lower tube voltage resulted in significant reduction in radiation exposure in noninvasive coronary CT angiography. Gopal et al. [28] showed in 149 patients using a 64-slice CT scanner that the combination of prospective ECG-triggered acquisition and $100 \mathrm{kV}$ images were of diagnostic quality, allowing adequate assessment in all patients. The prospective ECG-Triggered acquisition and $100 \mathrm{kV}$ 
images were of diagnostic quality, allowing adequate assessment in all patients. Steigner et al. [29] evaluated the relationship between the phase window width and image quality in prospectively ECG-gated 320detector row coronary CT angiography. The authors showed that, using prospectively ECG-gated single heart beat coronary CT angiography, a phase window width of $10 \%$ reduced patient radiation and yielded diagnostic images in $>90 \%$ of patients. Heart rate control proved to be an important component of 320detector row prospectively gated $\mathrm{CT}$ dose reduction.

In the present study in the International Journal of Cardiovascular Imaging, Herzog et al. [30] evaluated 70 patients using prospectively ECG-triggered CT coronary angiography to establish the determinants of vessel contrast. All patients underwent low-dose CT angiography using body mass index (BMI)-adapted tube parameters and a fixed contrast material bolus. Mean radiation dose was $2.13 \pm 0.69 \mathrm{mSv}$. Tube voltage had been adapted to patients' body mass index in order to minimize the interference of body mass index with image noise and, thus, contrast to noise ratio. With this strategy it was aimed at assessing the impact of cardiac output as an index of contrast bolus dilution on coronary artery attenuation and contrast to noise ratio. It was shown that a BMI adapted protocol widely reduced the impact of BMI on image noise, while vessel contrast remained subject to large variations, depending on bolus dilution by blood volume and cardiac output. The use of a BMI-adapted scanning protocol allowed the reduction of BMI interference on image noise as evidenced by similar noise values over a large range of BMI. Finally, the study identified body surface area as the most promising parameter to be of potential value for adjusting the contrast bolus in future protocols. As such, the present study by Herzog et al. [30] supports the notion that reduction of radiation exposure through low-dose CT angiography with prospective gating allows for proper vessel contrast using contrast dosages based on body surface area. These findings are in line with the recent findings of the same group guided by Kaufmann et al. [31, 32]), who showed that prospective ECG-triggering for CT angiography reduces radiation dose by almost $90 \%$ without affecting diagnostic performance. Consequently, striving for effective strategies to reduce radiation exposure-as well as implementing these strategies - are of paramount importance when evaluating patients undergoing CT angiography.
Open Access This article is distributed under the terms of the Creative Commons Attribution Noncommercial License which permits any noncommercial use, distribution, and reproduction in any medium, provided the original author(s) and source are credited.

\section{References}

1. van Werkhoven JM, Schuijf JD, Jukema JW et al (2008) Anatomic correlates of a normal perfusion scan using 64slice computed tomographic coronary angiography. Am J Cardiol 101:404-405

2. Pundziute G, Schuijf JD, Jukema JW et al (2007) Prognostic value of multislice computed tomography coronary angiography in patients with known or suspected coronary artery disease. J Am Coll Cardiol 49:62-70

3. Schuijf JD, Pundziute G, Jukema JW et al (2006) Diagnostic accuracy of 64-slice multislice computed tomography in the noninvasive evaluation of significant coronary artery disease. Am J Cardiol 98:145-148

4. Schuijf JD, Wijns W, Jukema JW et al (2006) Relationship between noninvasive coronary angiography with multislice computed tomography and myocardial perfusion imaging. J Am Coll Cardiol 48:2508-2514

5. Jongbloed MR, Lamb HJ, Bax JJ et al (2005) Noninvasive visualization of the cardiac venous system using multislice computed tomography. J Am Coll Cardiol 45:749-753

6. Groen JM, Greuter MJ, Vliegenthart R et al (2008) Calcium scoring using 64-slice MDCT, dual source CT and EBT: a comparative phantom study. Int $\mathrm{J}$ Cardiovasc Imaging 24:547-556

7. de Nooijer R, Verkleij CJ, von der Thüsen JH et al (2006) Lesional overexpression of matrix metalloproteinase-9 promotes intraplaque hemorrhage in advanced lesions but not at earlier stages of atherogenesis. Arterioscler Thromb Vasc Biol 26:340-346

8. Henneman MM, Schuijf JD, Pundziute G et al (2008) Noninvasive evaluation with multislice computed tomography in suspected acute coronary syndrome: plaque morphology on multislice computed tomography versus coronary calcium score. J Am Coll Cardiol 52:216-222

9. Budoff MJ, Shaw LJ, Liu ST et al (2007) Long-term prognosis associated with coronary calcification: observations from a registry of 25, 253 patients. J Am Coll Cardiol 49:1860-1870

10. van Lennep JE, Westerveld HT, van Lennep HW, Zwinderman AH, Erkelens DW, van der Wall EE (2000) Apolipoprotein concentrations during treatment and recurrent coronary artery disease events. Arterioscler Thromb Vasc Biol 20:2408-2413

11. van de Wal RM, van Werkum JW, le Cocq d'Armandville MC et al (2007) Giant aneurysm of an aortocoronary venous bypass graft compressing the right ventricle. Neth Heart J 15:252-254

12. de Leeuw JG, Wardeh A, Sramek A, van der Wall EE (2007) Pseudo-aortic dissection after primary PCI. Neth Heart J 15:265-266

13. Braun S, van der Wall EE, Emanuelsson S, Kobrin I (1996) Effects of a new calcium antagonist, mibefradil (Ro 40- 
5967), on silent ischemia in patients with stable chronic angina pectoris: a multicenter placebo-controlled study. The mibefradil international study group. J Am Coll Cardiol 27:317-322

14. ten Kate GJ, Wuestink AC, de Feyter PJ (2008) Coronary artery anomalies detected by MSCT-angiography in the adult. Neth Heart J 16:369-375

15. Schuijf JD, Jukema JW, van der Wall EE, Bax JJ (2007) Multi-slice computed tomography in the evaluation of patients with acute chest pain. Acute Card Care 9:214-221

16. van der Wall EE, den Hollander W, Heidendal GA, Westera G, Majid PA, Roos JP (1981) Dynamic myocardial scintigraphy with $123 \mathrm{I}$-labeled free fatty acids in patients with myocardial infarction. Eur J Nucl Med 6:383-389

17. Hoogendoorn LI, Pattynama PM, Buis B, van der Geest RJ, van der Wall EE, de Roos A (1995) Noninvasive evaluation of aortocoronary bypass grafts with magnetic resonance flow mapping. Am J Cardiol 75:845-848

18. van der Wall EE, Vliegen HW, de Roos A, Bruschke AV (1995) Magnetic resonance imaging in coronary artery disease. Circulation 92:2723-2739

19. Tops LF, Bax JJ, Zeppenfeld K et al (2005) Fusion of multislice computed tomography imaging with three-dimensional electroanatomic mapping to guide radiofrequency catheter ablation procedures. Heart Rhythm 210:1076-1081

20. Wijpkema JS, Dorgelo J, Willems TP et al (2007) Discordance between anatomical and functional coronary stenosis severity. Neth Heart J 15:5-11

21. Schuijf JD, Bax JJ, van der Wall EE (2007) Anatomical and functional imaging techniques: basically similar or fundamentally different? Neth Heart J 15:43-44

22. Budoff MJ, Dowe D, Jollis JG et al (2008) Diagnostic performance of 64-multidetector row coronary computed tomographic angiography for evaluation of coronary artery stenosis in individuals without known coronary artery disease: results from the prospective multicenter ACCURACY (Assessment by Coronary Computed Tomographic
Angiography of Individuals Undergoing Invasive Coronary Angiography) trial. J Am Coll Cardiol 52:1724-1732

23. Nissen SE (2008) Limitations of computed tomography coronary angiography. J Am Coll Cardiol 52:2145-2147

24. Schoenhagen P, Reiber H (2009) Focus on radiation exposure from cardiovascular imaging with computed tomography. Int J Cardiovasc Imaging 25:417-419

25. Hausleiter J, Meyer T, Hermann F et al (2009) Estimated radiation dose associated with cardiac CT angiography. JAMA 301:500-507

26. Hausleiter J, Meyer T (2008) Tips to minimize radiation exposure. J Cardiovasc Comput Tomogr 2:325-327

27. Pflederer T, Rudofsky L, Ropers D et al (2009) Image quality in a low radiation exposure protocol for retrospectively ECG-gated coronary CT angiography. AJR Am J Roentgenol 192:1045-1050

28. Gopal A, Mao SS, Karlsberg D et al (2009) Radiation reduction with prospective ECG-triggering acquisition using 64-multidetector computed tomographic angiography. Int J Cardiovasc Imaging 25:405-416

29. Steigner ML, Otero HJ, Cai T et al (2009) Narrowing the phase window width in prospectively ECG-gated single heart beat 320-detector row coronary CT angiography. Int J Cardiovasc Imaging 25:85-90

30. Herzog BA, Lars Husmann L, Valenta I et al (2009) Determinants of vessel contrast in BMI-adapted low dose CT coronary angiography with prospective ECG-triggering. Int J Cardiovasc Imaging. doi:10.1007/s10554-009-9460-3

31. Husmann L, Herzog BA, Gaemperli O et al (2009) Diagnostic accuracy of computed tomography coronary angiography and evaluation of stress-only single-photon emission computed tomography/computed tomography hybrid imaging: comparison of prospective electrocardiogramtriggering vs. retrospective gating. Eur Heart J 30:600-607

32. Herzog BA, Husmann L, Landmesser U, Kaufmann PA (2009) Low-dose computed tomography coronary angiography and myocardial perfusion imaging: cardiac hybrid imaging below 3mSv. Eur Heart J 30:644 